\title{
Physiological Basis of the Selective Advantage of a Spirillum sp. in a Carbon-limited Environment
}

\author{
By A. MATIN \\ Department of Medical Microbiology, Stanford University, Stanford, California 94305, U.S.A. \\ AND H. VELDKAMP \\ Department of Microbiology, State University of Groningen, Haren (Gr.), The Netherlands
}

(Received 12 September 1977; revised 14 November 1977)

\begin{abstract}
A Spirillum sp. and a Pseudomonas sp. possessing crossing substrate saturation curves for L-lactate were isolated from fresh water by chemostat enrichment. Their $K_{s}$ and $\mu_{\max }$ values for L-lactate were: Spirillum sp., $23 \mu \mathrm{m}$ and $0.35 \mathrm{~h}^{-1}$, respectively; Pseudomonas sp., $91 \mu \mathrm{M}$ and $0.64 \mathrm{~h}^{-1}$, respectively. Under L-lactate limitation, Pseudomonas sp. outgrew Spirillum sp. at dilution rates $(D)$ above $0.29 \mathrm{~h}^{-1}$, but the converse occurred at lower $D$ values. The advantage of Spirillum sp. increased with decreasing $D$ until, at $D=0.05 \mathrm{~h}^{-1}$ (i.e. L-lactate concentration of approximately $1 \mu \mathrm{M}$ ), Pseudomonas sp. was eliminated from the culture essentially as a non-growing population. In Spirillum sp. the $K_{\mathrm{m}}$ for L-lactate transport $(5.8 \mu \mathrm{M})$ was threefold lower than in Pseudomonas sp. $(20 \mu \mathrm{M})$; Spirillum sp. also possessed a higher $V_{\max }$ for the transport of this substrate. The surface to volume ratio was higher in Spirillum sp. and increased more markedly than in Pseudomonas sp. in response to decreasing $D$. Thus, a more efficient scavenging capacity contributes to the advantage of Spirillum sp. at low concentrations of the carbon source. Although most of the enzymes of L-lactate catabolism were more active in Pseudomonas sp., NADH oxidase activity was about twice as high in Spirillum sp.; and, unlike Pseudomonas sp., the cytochrome $c$ content of this bacterium increased markedly with decreasing $D$. A more active and/or more efficient respiratory chain may therefore also play a role in the advantage of Spirillum sp. The other factors which appear to be involved include a lower energy of maintenance of Spirillum sp. [0.016 g L-lactate (g cell dry wt) ${ }^{-1} \mathrm{~h}^{-1}$ compared with 0.066 in Pseudomonas sp.] and a lower minimal growth rate.
\end{abstract}

\section{INTRODUCTION}

With the chemostat it is possible to investigate microbial selection and competition at different concentrations of a growth-limiting nutrient (Jannasch, 1967; Veldkamp \& Jannasch, 1972; Veldkamp, 1976; Harder, Kuenen \& Matin, 1977). Jannasch (1967) found that with a low, and growth-limiting, concentration of lactate added to a sample of sea water, a bacterial species was selected which was different from that selected at higher concentrations of the same substrate. Kuenen et al. (1977) reported that enrichment at different concentrations of phosphate as growth-limiting nutrient in the medium also led to the selection of different bacterial species. The bacteria selected at different concentrations of a growth-limiting substrate possessed substrate saturation curves which crossed over (see Fig. 1): those selected at the low concentration had a low saturation constant $\left(K_{*}\right)$ and low maximum specific growth rate $\left(\mu_{\max }\right)$; those selected at the higher concentration had a higher $K_{*}$ and a higher $\mu_{\text {max }}$. Subsequent studies have shown that bacteria with a low $K_{\mathrm{s}}$ also invariably have a relatively low $\mu_{\mathrm{max}}$. Since aquatic environments generally 
contain low concentrations of nutrients (Duursma, 1961), it was inferred that the low $K_{*}$-low $\mu_{\text {mix }}$ type of bacteria play a dominant role in microbial transformations in these environments. Such bacteria are not isolated by traditional batch culture enrichments which, due to their high nutrient concentration, select exclusively for organisms with a high $\mu_{\max }$ (Veldkamp \& Jannasch, 1972; Harder et al., 1977). Little information exists on the physiology and ecology of this potentially important group of bacteria since nearly all the bacterial species which have been studied were isolated from batch culture enrichments.

This study was undertaken to investigate the physiological and biochemical basis of the capacity for relatively faster growth at low concentrations of carbon compounds. The low $K_{s}$-low $\mu_{\max }$ and high $K_{s}$-high $\mu_{\max }$ types of bacteria (a Spirillum sp. and a Pseudomonas sp., respectively) were isolated from a freshwater pond and a broad comparison was made of their characteristics during growth on different concentrations of l-lactate in chemostat culture. A preliminary report of these findings has been presented (Matin \& Veldkamp, 1974) and different aspects of the physiology of these bacteria have been examined (Matin \& Konings, 1973; Matin, Grootjans \& Hogenhuis, 1976; Matin \& Gottschal, 1976).

\section{METHODS}

Growth conditions and enrichment procedure. The basal mineral salts medium contained $\left(\mathrm{g} \mathrm{I}^{-1}\right): \mathrm{K}_{2} \mathrm{HPO}_{4}$. $3 \mathrm{H}_{2} \mathrm{O}, 1 \cdot 13 ; \mathrm{KH}_{2} \mathrm{PO}_{4}$ (anhydrous), $0 \cdot 88 ; \mathrm{NH}_{4} \mathrm{Cl}, 1 \cdot 00 ; \mathrm{MgSO}_{4} .7 \mathrm{H}_{2} \mathrm{O}, 0.50 ; \mathrm{NaCl}, 1.00 ; \mathrm{CaCl}_{2} .2 \mathrm{H}_{2} \mathrm{O}$, 0.005 ; and $1.20 \mathrm{ml}$ of the trace elements solution of Vishniac \& Santer (1957). This medium was supplemented separately with lactate, succinate or L-alanine to $0.5 \mathrm{~g} \mathrm{I}^{-1}$ to obtain culture media limiting in these carbon sources. The media were prepared and sterilized as previously described (Matin et al., 1976). Enrichment and competition experiments were carried out at $28{ }^{\circ} \mathrm{C}$ in a chemostat with a working volume of $200 \mathrm{ml}$. The $\mathrm{pH}$ was automatically maintained at $7 \cdot 0 \pm 0 \cdot 1$ by adding sterile $0 \cdot 2 \mathrm{M}-\mathrm{HCl}$ solution. The oxygen concentration in the culture vessel was periodically monitored by an oxygen electrode and was never below $80 \%$ air saturation. The flow rate of fresh medium into the culture vessel was controlled with a peristaltic pump (LKB, Varioperpex, 12000). The inflowing air was passed through a water column (about $25 \mathrm{~cm}$ long) to minimize evaporation of the culture fluid. Other features of the chemostat were as described by Veldkamp (1976).

For enrichment, L-lactate-limited medium was supplied to two identical chemostats from a $15 \mathrm{I}$ reservoir. Each of the vessels was inoculated with $10 \mathrm{ml}$ of a sample from a freshwater pond which had been passed through a $1.2 \mu \mathrm{m}$ membrane filter to remove debris and larger organisms such as protozoa. After $24 \mathrm{~h}$ of batch culture, the fresh medium flow was initiatec to give dilution rates $(D)$ of $0.05 \mathrm{~h}^{-1}$ in one vessel and $0.30 \mathrm{~h}^{-1}$ in the other. Different dominant bacterial populations were found in the two vessels after approximately five volume changes and these were isolated by repeated streaking on solid L-lactate medium (composition as described above, but with $20 \mathrm{~g}$ agar $1^{-1}$ added). Stock cultures of the two bacteria were maintained on the same medium. These bacteria have been deposited with Deutsche Sammlung von Mikroorganismen, München, West Germany. The accession numbers are: Spirillum sp., DSM 1109; Pseudomonas sp., DSM 1110.

Procedure for competition experiments. The organisms were pre-grown in either batch or continuous culture at the dilution rate to be used in the competition experiment. They were harvested aseptically, mixed in suitable proportion and inoculated in a chemostat run at the specified $D$ value. The inoculum size was

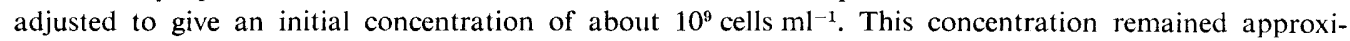
mately constant during the experiment, only the relative proportions of the two bacteria changing. Saturating initial cell densities were employed to ensure rapid establishment of L-lactate limitation. At $D=0.05 \mathrm{~h}^{-1}$, viable cell counts were begun after the chemostat had been run for $4 \mathrm{~h}$; at other $D$ values, measurements were begun immediately after the two populations were mixed in the chemostat. Viable counts on samples removed during competition experiments were determined by spreading appropriate dilutions on L-lactate agar plates. Colonies of the two bacteria could be easily distinguished by their size and shape.

The washout rate of a non-growing population from the chemostat vessel was calculated from the equation (Jannasch, 1969):

$$
\ln X_{2}=\ln X_{1}\left(t_{2}-t_{1}\right) D
$$

where $X_{2}$ is the number of the non-growing population at a given time $\left(t_{2}\right)$ to be determined, and $X_{1}$ is the number of this population at any previous time $\left(t_{1}\right)$. 
The difference in the growth rates of the two populations in the competition experiments was calculated from the equation:

$$
\left(\mu_{1}-\mu_{2}\right)=\frac{\ln R_{2}-\ln R_{1}}{t}
$$

where $\mu_{1}$ and $\mu_{2}$ are the specific growth rates of the two populations, $R_{2}$ is the ratio of the two populations at a given time $\left(t_{2}\right), R_{1}$ is this ratio at any previous time $\left(t_{1}\right)$, and $t=t_{2}-t_{1}$.

Culture viability determination. The percentage viability of the two bacteria in chemostat cultures at various $D$ values was determined by the slide-culture technique (Postgate, 1969). For this, $0.2 \mathrm{ml} \mathrm{of} 0.01 \%$ $(\mathrm{w} / \mathrm{v})$ L-lactate medium [supplemented with $2 \%(\mathrm{w} / \mathrm{v})$ prefiltered agar] was allowed to set in stainless steel rings (inner diameter, $17 \mathrm{~mm}$; height, $1 \mathrm{~mm}$ ) placed on glass slides. A low L-lactate concentration was used to approximate as closely as possible to the conditions of the chemostat environment and to minimize the possibility of substrate-accelerated death (Calcott \& Postgate, 1972). A suitable dilution of the culture was spread on the surface of the agar, so that each microscopic field at $400 \times$ magnification contained about 50 organisms. The slides were incubated in a moist atmosphere at $28{ }^{\circ} \mathrm{C}$ and examined under a phasecontrast microscope every $3 \mathrm{~h}$ for up to $28 \mathrm{~h}$. Each single cell was counted as one dead unit, each microcolony as one viable unit. Each time 400 to 500 units were counted and the percentage viability was calculated from the numbers of viable and dead cells. The maximum value was usually attained by $21 \mathrm{~h}$ of incubation.

Energy of maintenance determination. Maintenance energy on L-lactate was determined by plotting $1 / D$ against $1 / Y$, where $Y$ is the $\mathrm{g}$ dry weight cell material formed ( $\mathrm{g}$ L-lactate consumed) ${ }^{-1}$, as described by Pirt (1975). To determine $Y$ at various $D$ values, the organisms were grown in separatechemostats of $700 \mathrm{ml}$ working volume, using $0 \cdot 2 \%(\mathrm{w} / \mathrm{v})$ L-lactate medium. After a steady state was established at a given $D$, a $200 \mathrm{ml}$ sample was removed, cooled and immediately centrifuged $(8300 \mathrm{~g} ; 20 \mathrm{~min})$. The pellet was resuspended in $10 \mathrm{ml} \mathrm{H} \mathrm{H}_{2} \mathrm{O}$ and quantitatively transferred to vials which had been pre-dried and weighed; the cells were not washed because of the predisposition of Pseudomonas sp. to lysis. The vials were dried to constant weight in an oven at $110^{\circ} \mathrm{C}$.

Saturation constant and maximum specific growth rate determinations. The saturation constant, $K_{\star}$, was calculated from the equation:

$$
K_{s}=\frac{\bar{s}\left(\mu_{\max }-D\right)}{D}
$$

where $\bar{s}$ is the steady-state L-lactate concentration in the culture vessel at a given dilution rate $(D)$, and $\mu_{\text {wax }}$ is the maximum specific growth rate of the bacterium.

To determine $\bar{s}$, each organism was grown separately at $D=0.15 \mathrm{~h}^{-1}$ in a chemostat with $600 \mathrm{ml}$ working volume (Bioflo, New Brunswick Scientific Co), using L-lactate-limited medium (L-lactate concentration, $0.025 \%$, w/v). After five volume changes (approximately seven generations), four samples (each approximately $4 \mathrm{ml}$ ) were taken from each culture using a manifold, and filtered under vacuum. Millipore membrane filters (diam. $47 \mathrm{~mm}$; pore size, $0.45 \mu \mathrm{m}$ ) were used and filtration was accomplished within $30 \mathrm{~s}$ to $1 \mathrm{~min}$. Calculations based on the known respiratory capacity of the cells (see Fig. 5) and their $K_{s}$ for L-lactate respiration (Matin \& Konings, 1973) indicated that less than $1 \%$ of the L-lactate in the culture filtrates could have been respired during sample collection. Portions $(3 \mathrm{ml})$ of the filtrates were dried in a stream of air, resuspended in $1 \mathrm{ml}$ distilled, deionized water and used in the L-lactate determination. Assay mixtures for L-lactate determination (Hohorst, 1963) contained (total volume, $1 \mathrm{ml}$ ): $0.5 \mathrm{ml}$ of $0.4 \mathrm{M}$-hydrazine sulphate buffer, $\mathrm{pH} 9.5 ; 0.05 \mathrm{ml}$ of $0.05 \mathrm{M}-\mathrm{NAD}$; up to $0.43 \mathrm{ml}$ of sample; and $0.02 \mathrm{ml}$ of rabbit muscle L-lactate dehydrogenase (1500 I.U. $\mathrm{ml}^{-1}$; Calbiochem). Lactate concentration in the sample was calculated from $\Delta A_{340}$ recorded spectrophotometrically; $\epsilon_{\mathrm{NADH}}=6.22 \times 10^{6} 1 \mathrm{~mol}^{-1} \mathrm{~cm}^{-1}$.

To determine $\mu_{\max }$, the bacteria were grown in batch cultures in $100 \mathrm{ml}$ medium containing $0.2 \%(\mathrm{w} / \mathrm{v})$ L-lactate in $250 \mathrm{ml}$ Erlenmeyer flasks shaken at $28^{\circ} \mathrm{C}$, and $\Delta A_{660}$ was measured. The purity of the cultures was checked by streaking on $0.05 \%(\mathrm{w} / \mathrm{v})$ L-lactate and nutrient agar plates.

The Michaelis-Menten constant for L-lactate transport. Cells were grown in batch cultures in $0 \cdot 2 \%(\mathrm{w} / \mathrm{v})$ L-lactate medium and harvested from late-exponential phase. They were washed three times in $0.1 \mathrm{M}-$ potassium phosphate buffer, $\mathrm{pH} 6.6$, and resuspended in the same buffer to a density of approximately $3.5 \mathrm{mg}$ cell protein $\mathrm{ml}^{-1}$. The uptake experiments were carried out as described by Matin \& Konings (1973). The reaction mixtures contained (total volume, $100 \mu \mathrm{l}$ ): $50 \mathrm{~mm}$-potassium phosphate buffer, pH 6.6; $10 \mathrm{mM}^{-} \mathrm{MgSO}_{4} ; 0.02$ to $0.07 \mathrm{mg}$ cell protein; and 1 to $20 \mu \mathrm{M}-\mathrm{L}-\left[\mathrm{U}-{ }^{14} \mathrm{C}\right]$ lactate $\left(40 \mathrm{mCi} \mathrm{mmol}^{-1}\right.$; The Radiochemical Centre, Amersham). L-Lactate uptake was initially determined at 1, 3 and $20 \mu \mathrm{M}$, taking samples every $15 \mathrm{~s}$. As the uptake was linear up to $45 \mathrm{~s}$ with $1 \mu \mathrm{M}$-L-lactate and up to $1 \mathrm{~min}$ or longer at other concentrations, the $K_{\mathrm{m}}$ values were determined by following uptake for $30 \mathrm{~s}$ at each concentration of L-lactate; see Matin \& Konings (1973) for further details.

Surface to volume ratio. From steady-state cultures of Pseudomonas sp. and Spirillum sp. growing in separate chemostat vessels at various dilution rates under L-lactate- or succinate-limitation, $20 \mathrm{ml}$ samples 
were taken, centrifuged, washed in $0 \cdot 1 \mathrm{M}$-ammonium acetate buffer, stained with $1 \%(\mathrm{w} / \mathrm{v})$ uranyl acetate and pholographed, using a Philips EM300 electron microscope.

Each cell was considered to be made up of a cylinder and a sphere. The surface area and volume of the cylindrical part were calculated as $2 \pi R h$ and $\pi R^{2} h$, respectively, where $h$ is the height of the cylinder and $R$ is its radius; the volume and surface area of the spherical part were calculated as $4 \pi R^{2}$ and $4 \pi R^{3} / 3$, respectively, where $R$ is the radius of the sphere. $R$ was measured at the centre of a cell and was assumed to be identical for its cylindrical and spherical parts.

Analyses. Cell extracts were prepared and enzyme activities were measured as described by Matin $e f$ al. (1976). The reaction mixture for estimating total cytochrome $c$ content contained (total volume, $1 \mathrm{ml}$ ): $50 \mu \mathrm{mol}$ potassium phosphate buffer, $\mathrm{pH} 7 \cdot 0 ; 2.5$ to $3 \mathrm{mg}$ crude cell extract protein; and a few crystals of sodium dithionite (sample cuvette) or $0.05 \mu \mathrm{nol} \mathrm{K}{ }_{3} \mathrm{Fe}(\mathrm{CN})_{6}$ (reference cuvette). Absorption spectra were obtained using a Cary 14 recording spectrophotometer and $\Delta A_{555}-\Delta A_{540}$ was used to calculate the cytochrome $c$ content (for reduced cytochrome $c, \epsilon=19 \cdot 1 \times 10^{6} 1 \mathrm{~mol}^{-1} \mathrm{~cm}^{-1}$ ).

The respiratory capacity of the organisms grown at different $D$ values was determined by quickly transferring organisms from a steady-state culture to a biological oxygen monitor (Yellow Springs Instrument Co., Yellow Springs, Ohio, U.S.A.). The oxidation rate of L-lactate was determined using a reaction mixture which contained (total volume, $3 \mathrm{ml}$ ): $50 \mathrm{~mm}$-potassium phosphate buffer, pH $7 \cdot 0 ; 0.1$ 10 $0.2 \mathrm{mg}$ cell protein; and 8 mm-sodium L-lactate. Oxygen uptake was measured at $29 \mathrm{C}$ for a period of 2 to $5 \mathrm{~min}$; see Matin \& Konings (1973) for further details.

Nucleic acids were determined by the method of Munro \& Fleck (1966), and protein by that of Lowry et al. (1951).

\section{RESULTS}

\section{Isolation and $K_{\mathrm{s}}$ values}

A small, non-motile Spirillum sp. became the dominant population at $D=0.05 \mathrm{~h}^{-1}$, and a motile Pseudomonas sp. at $D=0 \cdot 30 \mathrm{~h}^{-1}$. This dominance became apparent within five volume changes and persisted for as long as the experiment was continued (10 volume changes). The $\mu_{\max }$ values on L-lactate were: for Spirillum sp., $0.35 \mathrm{~h}^{-1}$; and for Pseudomonas sp., $0.64 \mathrm{~h}^{-1}$. At $D=0.15 \mathrm{~h}^{-1}$, the residual L-lactate concentrations (average of four determinations \pm S.E.M.; see Methods) were: for Spirillum sp., $0.017 \pm 0.003 \mu \mathrm{mol} \mathrm{ml}^{-1}$; and for Pseudomonas sp., $0.028 \pm 0.004 \mu \mathrm{mol} \mathrm{m} l^{-1}$. Thus the $K_{s}$ values were calculated to be: for Spirillum sp., $23 \mu \mathrm{m}$; and for Pseudomonas sp., $91 \mu \mathrm{M}$. From these data the substrate saturation curves of the two bacteria were calculated (Fig. 1), employing equation (3). The $K_{\mathrm{s}}$ of Spirillum sp. for L-lactate was approximately fourfold lower than that of Pseudomonas sp. and the crossing point of the curve was at about $D=0.25 \mathrm{~h}^{-1}$.

\section{Kinetics of competition}

Competition between the two bacteria was studied with a mixed culture growing in a chemostat operating at various $D$ values, with L-lactate as the limiting nutrient (Fig. 2). At $D \leqslant 0.24 \mathrm{~h}^{-1}$, Spirillum sp. outcompeted Pseudomonas sp. and its advantage became more pronounced with decreasing $D$; indeed at $D=0.05 \mathrm{~h}^{-1}$, the ratio Pseudomonas sp./ Spirillum sp. changed at a rate that indicated that under these conditions Pseudomonas sp. was not appreciably multiplying. At $D \geqslant 0.29 \mathrm{~h}^{-1}$ Pseudomonas sp. outgrew Spirillum sp. (the kinetics of competition are shown ir Fig. 2 only for $D=0.32 \mathrm{~h}^{-1}$ ). Similar results were obtained regardless of whether the inocula for the competition experiments were grown in batch or continuous culture. The possible influence of population density on these results was checked by increasing the L-lactate concentration in the inflow medium to $0.2 \%$ and studying competition at a low $\left(0.05 \mathrm{~h}^{-1}\right)$ and a high $\left(0.28 \mathrm{~h}^{-1}\right) \mathrm{D}$ value. The outcome, which was judged qualitatively by microscopic examination, agreed with previous findings. Thus, an approximately fourfold change in population density did not affect the outcome of competition.

The average difference in the specific growth rates of the two organisms during competition was calculated from the data of Fig. 2 using equation (2). At $D=0.05$ and $0.24 \mathrm{~h}^{-1}$, at which Spirillum sp. won the competition, this difference was about 0.06 and $0.11 \mathrm{~h}^{-1}$, 


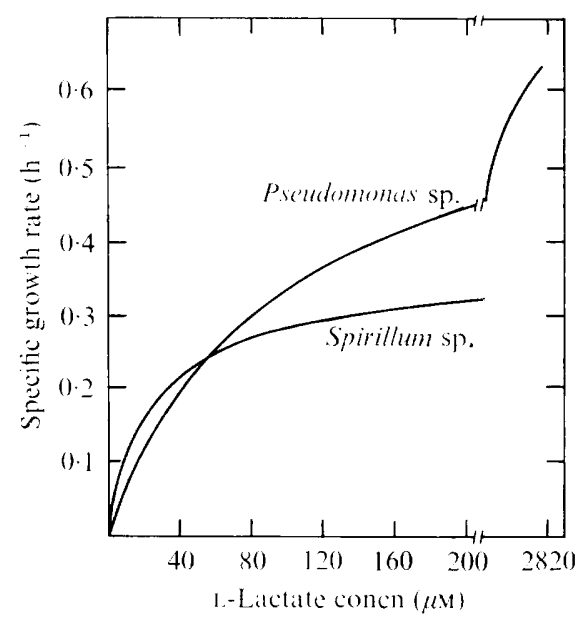

Fig. 1

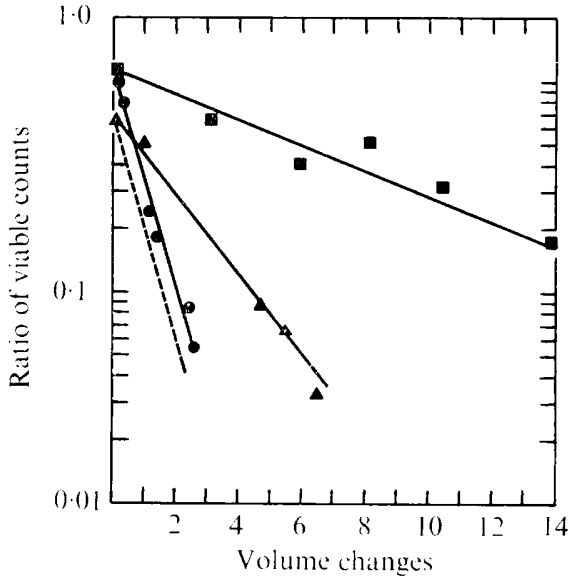

Fig. 2

Fig. 1. Substrate saturation curves for L-lactate of Spirillum sp. and Pseudomonas sp. calculated from $K_{s}$ and $\mu_{\max }$ data; $\mu_{\text {max }}$ was determined as described in the text and $K_{s}$ was calculated from the residual L-lactate concentration in the culture medium at $D=0.15 \mathrm{~h}^{-1}$. The growth constants for the two bacteria are: Spirillum sp.: $\mu_{\max }, 0.35 \mathrm{~h}^{-1}, K_{s}, 23 \mu_{\mathrm{M}} ;$ Pseudomonas sp.: $\mu_{\max }, 0.64 \mathrm{~h}^{-1}$, $K_{s}, 91 \mu \mathrm{M}$.

Fig. 2. Ratio of viable counts of Pseudomonas sp. and Spirillum sp., during competition in a mixed culture with L-lactate as limiting nutrient, as a function of growth rate (the abscissa shows the number of complete changes of medium that have passed through the chemostat). $D=0 \cdot 05 \mathrm{~h}^{-1}$

(O), $0.24 \mathrm{~h}^{-1}(\mathbf{A})$ and $0.32 \mathrm{~h}^{-1}(\mathbf{D})$. The dashed line indicates the change in this ratio if the organism losing the competition were being eliminated as a non-growing population (calculated from equation 1). The ordinate specifies the ratio of Pseudomonas sp. to Spirillum $\mathrm{sp}$. $(\mathbf{O}, \mathbf{\Delta})$, or

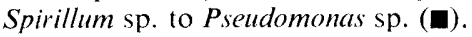

respectively. This observed difference, especially at $D=0 \cdot 24 \mathrm{~h}^{-\mathbf{1}}$, is much greater than predicted by the Monod relationships (Fig. 1); according to these relationships the maximum difference in the specific growth rates of the two organisms, at $D$ values where Spirillum sp. wins the competition, is about $0.04 \mathrm{~h}^{-1}$. The advantage of Spirillum sp. during competition cannot, therefore, be explained solely on the basis of these Monod relationships. To test whether Spirillum sp. excreted an inhibitor of the growth of Pseudomonas sp., which may contribute to this advantage, a steady-state culture of Spirillum sp. at $D=0.05 \mathrm{~h}^{-1}$ was filtered, L-lactate was added to the filtrate to $0.2 \%(\mathrm{w} / \mathrm{v})$, and the resulting medium was inoculated with Pseudomonas sp. The organism grew at its usual rate indicating that no inhibitor had accumulated in the culture of Spirillum sp.

\section{Transport parameters and surface to volume ratio}

Spirillum sp. could owe its advantage over Pseudomonas sp. at low L-lactate concentrations to a high-affinity transport system for L-lactate. The kinetic constants for L-lactate transport were therefore determined for the two bacteria: Spirillum sp. had a threefold lower $K_{\mathrm{m}}$ value for L-iactate than Pseudomonas sp. $(5.8 \mu \mathrm{M}$ versus $20 \mu \mathrm{M}) ; V_{\max }$ for L-lactate transport was also significantly higher in Spirillum sp. [14.7 versus $10.0 \mathrm{nmol}$ L-lactate (mg protein $)^{-1}(30 ;)^{-1}$. Essentially identical values were obtained in two separate determinations. In both bacteria, $K_{\mathrm{m}}$ for L-lactate was approximately fourfold lower than $K_{\mathrm{s}}$ for growth on L-lactate.

Another reason for the ability of Spirillum sp. to grow more rapidly at low concentrations of L-lactate could be a higher surface/volume ratio in this organism compared with 


\section{Table 1. Effect of dilution rate on cell dimensions of Spirillum sp. and Pseudomonas sp. grown under L-lactate limitation}

\begin{tabular}{|c|c|c|c|c|c|c|c|c|c|c|}
\hline \multirow{2}{*}{$\begin{array}{l}\text { Dilution } \\
\text { rate } \\
\left(\mathrm{h}^{-1}\right)\end{array}$} & \multicolumn{2}{|c|}{ Length $(\mu \mathrm{m})$} & \multicolumn{2}{|c|}{ Breadth $(\mu \mathrm{m})$} & \multicolumn{2}{|c|}{$\begin{array}{l}\text { Surface area } \\
\qquad\left(\mu \mathrm{m}^{2}\right)\end{array}$} & \multicolumn{2}{|c|}{$\begin{array}{l}\text { Volume } \\
\left(\mu \mathrm{m}^{3}\right)\end{array}$} & \multicolumn{2}{|c|}{$\begin{array}{c}\text { Surface/ } \\
\text { volume } \\
\left(\mu \mathrm{m}^{1}\right)\end{array}$} \\
\hline & $S p$ & PS. & $S p$ & Ps. & $S p$ & $P s$. & $S p$ & $P s$ & $S p$ & Ps. \\
\hline $.01(50)$ & $2 \cdot 16 \pm 0 \cdot 05$ & $1.92 \pm 0.04$ & $0.47 \pm 0.004$ & $0.70 \pm 0.005$ & $3 \cdot 18$ & $4 \cdot 22$ & $0 \cdot 34$ & 0.65 & $9 \cdot 30$ & 6.49 \\
\hline $.06(40)$ & $2 \cdot 10 \pm 0.07$ & $2 \cdot 05 \pm 0.04$ & $0.55 \pm 0.005$ & $0.73 \pm 0.002$ & $3 \cdot 58$ & $4 \cdot 68$ & $0 \cdot 44$ & $0 \cdot 75$ & $8 \cdot 05$ & $6 \cdot 24$ \\
\hline $16(50)$ & $2 \cdot 21 \pm 0.06$ & $2 \cdot 26 \pm 0.07$ & $0.56 \pm 0.006$ & $0.80 \pm 0.004$ & $3 \cdot 89$ & $5 \cdot 70$ & $0 \cdot 50$ & $1 \cdot 01$ & $7 \cdot 82$ & $5 \cdot 66$ \\
\hline $27(50)$ & $2.40 \pm 0.06$ & $2 \cdot 39 \pm 0.05$ & $0.62 \pm 0.007$ & $0.83 \pm 0.006$ & $4 \cdot 69$ & $6 \cdot 20$ & $0 \cdot 67$ & $1 \cdot 13$ & $7 \cdot 04$ & $5 \cdot 49$ \\
\hline $33(43)$ & $2 \cdot 19 \pm 0 \cdot 05$ & $2.52 \pm 0.06$ & $0.67 \pm 0.006$ & $0.84 \pm 0.008$ & 4.57 & $6 \cdot 68$ & 0.69 & $1 \cdot 25$ & 6.67 & $5 \cdot 34$ \\
\hline $\begin{array}{c}0.35(50) \\
\text { (batch) }\end{array}$ & $2.17 \pm 0.05$ & - & $0.72 \pm 0.007$ & & $4 \cdot 89$ & 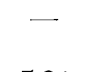 & $0 \cdot 78$ & 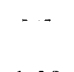 & $6 \cdot 27$ & $\ldots$ \\
\hline $0.46(49)$ & $\cdots$ & $2.75 \pm 0.07$ & - & $0.84 \pm 0.006$ & - & $7 \cdot 26$ & 一 & $1 \cdot 38$ & $-{ }_{-}^{-}$ & $5 \cdot 26$ \\
\hline $\begin{array}{c}0.64(50) \\
\text { (batch) }\end{array}$ & - & $3.55 \pm 0.09$ & - & $0.96 \pm 0.008$ & $一$ & $10 \cdot 66$ & - & $2 \cdot 32$ & $\ldots$ & $4 \cdot 59$ \\
\hline
\end{tabular}

Table 2. Comparison of enzyme activities of Spirillum sp. and Pseudomonas sp.

Organisms were grown at dilution rates of $0 \cdot() 4$ and $0 \cdot 28 \mathrm{~h}^{-1}$ under L-lactate limitation and enzyme activities were measured as described by Matin et al. (1976). Specific activities are expressed as $\mu$ mol substrate converted $\min ^{-1}$ (mg protein $)^{-1}$.

\section{Enzyme}

NAD-independent L-lactate dehydrogenase NAD-dependent L-lactate dehydrogenase (EC 1.1.1.27)

Aconitase (EC 4.2.1.3)

Isocitrate dehydrogenase (EC 1.1.1.42)

2-Oxoglutarate dehydrogenase (EC 1.2.4.2)

Glucose-6-phosphate dehydrogenase (EC 1.1.1.49)

NADH oxidase

\begin{tabular}{cc}
\multicolumn{2}{c}{$\begin{array}{c}\text { Specific activity at } \\
D=0.04 \mathrm{~h}^{-1}\end{array}$} \\
$\begin{array}{cc}\text { Pseudomonas } \\
\text { Spillum } \text { sp. }\end{array}$ \\
0.70 & 0.97 \\
1.10 & 2.40 \\
0.015 & 0.150 \\
1.05 & 1.20 \\
0.01 & 0.02 \\
0.034 & 0.076 \\
0.040 & 0.018
\end{tabular}

\begin{tabular}{|c|c|}
\hline \multicolumn{2}{|c|}{$\begin{array}{c}\text { Specific activity at } \\
D=0.28 \mathrm{~h}^{-1}\end{array}$} \\
\hline & Pseudomonas \\
\hline Spirillum sp. & sp. \\
\hline 0.34 & 0.54 \\
\hline $0 \cdot 55$ & 0.95 \\
\hline 0.01 & $0 \cdot 04$ \\
\hline $0 \cdot 96$ & 0.96 \\
\hline 0.005 & 0.018 \\
\hline 0.02 & 0.03 \\
\hline 0.07 & 0.04 \\
\hline
\end{tabular}

Pseudomonas sp., enabling it to concentrate a limiting nutrient more effectively. We therefore determined the cell dimensions of the two bacteria after growth at different $D$ values. Under L-lactate limitation (Table 1), the cell length of Spirillum sp. did not change significantly in response to changes in $D$, but in Pseudomonas sp. it decreased nearly linearly with decreasing $D$. Both the bacteria became thinner with decreasing $D$ values (Fig. 3): in Spirillum sp., the reduction in cell width was almost linear with decreasing $D$; in Pseudomonas sp., it was non-linear and less pronounced. At all $D$ values examined, cells of Pseudomonas sp. were wider than those of Spirillum sp.; cells of Spirillum sp. also showed a more pronounced curvature at low $D$ values (Fig. 3). It is generally believed that cell width is a constant characteristic of a bacterium; these data show that this is not the case.

Total surface area as well as total volume decreased with decreasing $D$ in both the bacteria, but the surface to volume ratio increased (Table 1). At all $D$ values, the surface to volume ratio was greater in Spirillum sp. than in Pseudomonas sp., and the difference became more pronounced at lower $D$ values because Spirillum sp. exhibited a greater increase in surface/volume ratio with decreasing $D$ than did Pseudomonas sp. 

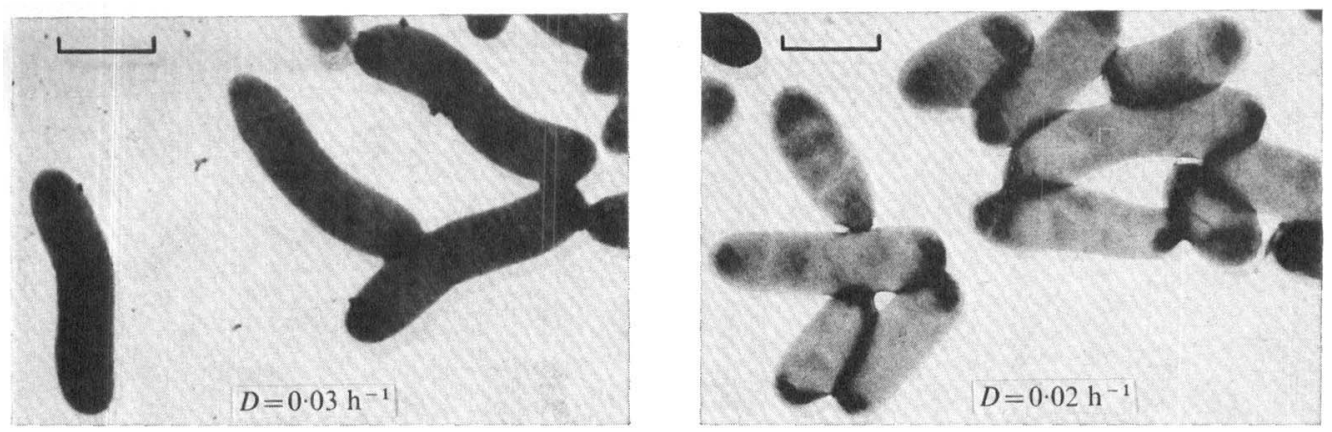

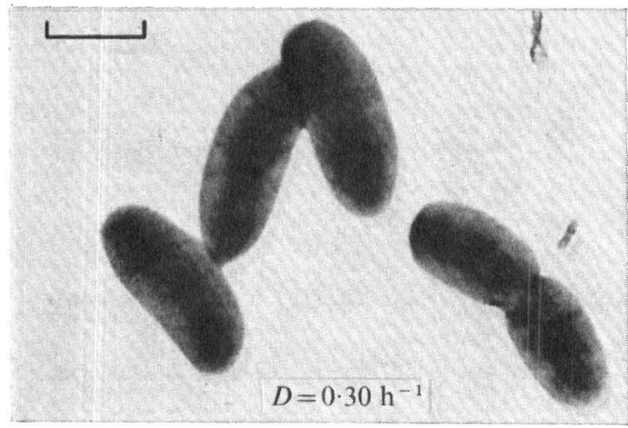

Spirillum sp.

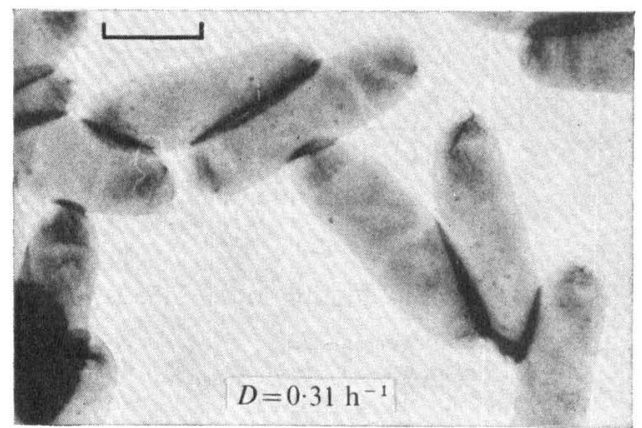

Pseudomonas sp.

Fig. 3. Effect of dilution rate on cell size and shape of Spirillum sp. and Pseudomonas sp. grown in L-lactate-limited medium. Bar markers represent $1 \mu \mathrm{m}$.

\section{Enzymes of intermediary metabolism}

Another reason for the advantage of Spirillum sp. could be that it has higher levels of enzymes of lactate catabolism. We therefore compared the specific activity of several enzymes of L-lactate metabolism in Spirillum sp. and Pseudomonas sp. Data are presented (Table 2) for two $D$ values, $0.04 \mathrm{~h}^{-1}$, at which in mixed cultures Spirillum sp. outcompetes Pseudomonas sp., and $0 \cdot 28 \mathrm{~h}^{-1}$, at which the converse occurs. At both $D$ values Pseudomonas sp. possessed higher levels of most of the enzymes examined. However, NADH oxidase activity was approximately twofold higher in Spirillum sp. at both the $D$ values. The two bacteria exhibited an interesting variation in their cytochrome $c$ content at different $D$ values (Fig. 4). At $D=0 \cdot 30 \mathrm{~h}^{-1}$, they contained similar levels of this enzyme; as $D$ was decreased, the level of cytochrome $c$ decreased slightly in Pseudomonas sp. but increased markedly in Spirillum sp. so that at low $D$ values (e.g. $0 \cdot 04 \mathrm{~h}^{-1}$ ) Spirillum sp. possessed three times as much cytochrome $c$ as Pseudomonas sp.

As has been discussed in detail elsewhere (Matin et al., 1976), both the organisms had higher activities of the enzymes examined, with the exception of NADH oxidase, after growth at the lower $D$ value (Table 2).

\section{Energy of maintenance}

The energy of maintenance (Pirt, 1975) was compared in the two organisms. The yield corrected for maintenance requirement on L-lactate was comparable in the two bacteria [0.38 and 0.41 g cell dry wt (g L-lactate consumed) ${ }^{-1}$ in Spirillum sp. and Pseudomonas sp., respectively], but the energy of maintenance was fourfold lower in Spirillum sp. [0.016 g L-lactate (g cell dry wt) $)^{-1} \mathrm{~h}^{-1}$ compared with 0.066 in Pseudomonas sp.]. 


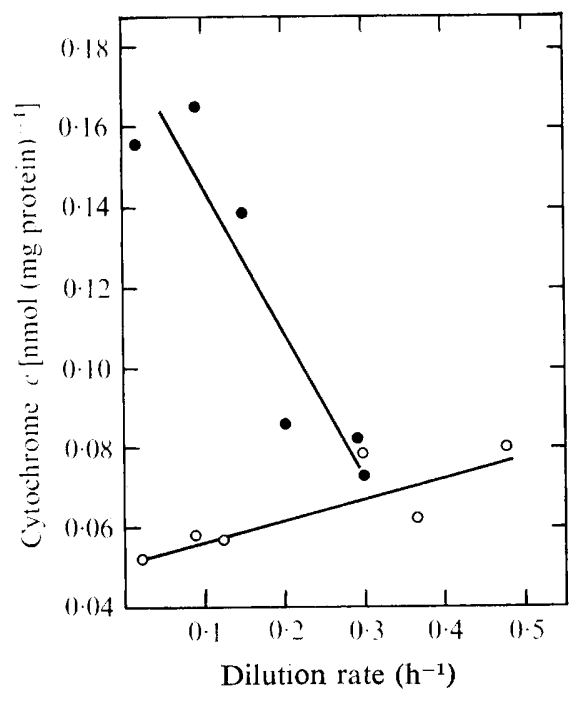

Fig. 4

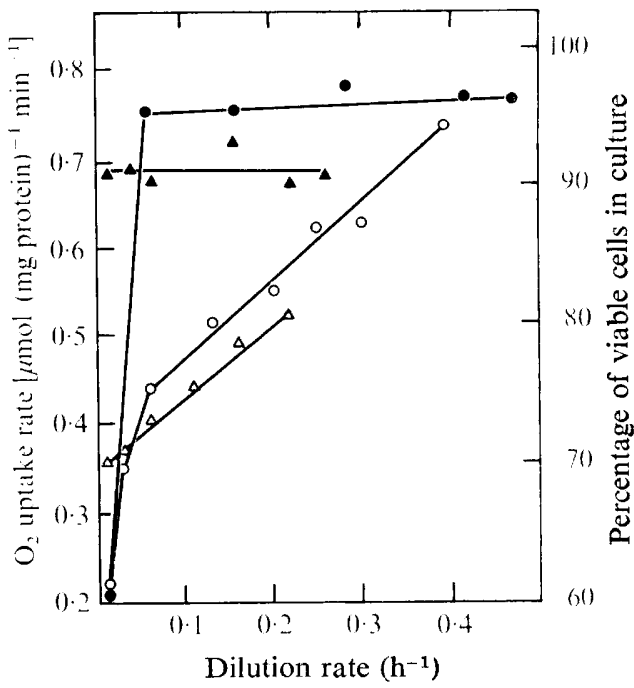

Fig. 5

Fig. 4. Effect of dilution rate on the levels of cytochrome $c$ in Spirillum sp. (O) and Pseudomonas sp. $(\bigcirc)$.

Fig. 5. Percentage viability $(\boldsymbol{\Lambda}, \boldsymbol{O})$ and respiratory capacity for L-lactate $(\triangle, O)$ in cultures of Spirillum sp. $(\boldsymbol{\Lambda}, \triangle)$ and Pseudomonas sp. $(\boldsymbol{O}, \bigcirc)$ as a function of dilution rate.

\section{Role of 'minimal growth rate'}

Recent evidence suggests that the growth rate of micro-organisms can be decreased only to a finite value, up to approximately $6 \%$ of their maximum rate of growth (Pirt, 1972). If so, the 'minimum' rate of growth $\left(\mu_{\min }\right)$ of Pseudomonas sp. would be approximately twofold higher than that of Spirilium sp. and this difference could contribute to the advantage of Spirillum sp. at low $D$ values. To check this point, we determined the viability of the cultures of the two bacteria at different $D$ values. This was between 90 and $98 \%$ at $D$ values between $0.47 \mathrm{~h}^{-1}$ and $0.05 \mathrm{~h}^{-1}$ (Fig. 5). Below $D=0.05 \mathrm{~h}^{-1}$, there was an abrupt decline in the percentage viability of the culture of Pseudomonas sp., but not of Spirillum sp. As a further check on the physiological state of the cultures of the two bacteria after growth at different $D$ values, we determined their maximal respiratory capacity for L-lactate. A sharp discontinuity was observed in the respiratory capacity of Pseudomonas sp. below $D=0.08 \mathrm{~h}^{-1}$ but not in that of Spirillum sp. (Fig. 5).

As has been pointed out by Pirt (1972), the data of Tempest, Herbert \& Phipps (1967) also showed sharp discontinuities in the RNA content of Klebsiella (Aerobacter) aerogenes, when it was grown at below $6 \%$ of its $\mu_{\text {max }}$. No such discontinuity could be discerned in the RNA or DNA content of Pseudomonas sp. at growth rates down to $4 \%$ of its $\mu_{\max }$. In both the bacteria, in the entire range of $D$ values examined $\left(0.02\right.$ to $\left.0.45 \mathrm{~h}^{-1}\right)$, the RNA content increased linearly with increasing, $D$, but the DNA content declined, somewhat slowly up to about $D=0 \cdot 2 \mathrm{~h}^{-1}$ and then more rapidly.

\section{DISCUSSION}

A comparative study has been made of several characteristics of Spirillum sp. and Pseudomonas sp. to aid understanding of the physiological basis of the advantage of the former bacterium at low L-lactate concentrations in the environment. Spirillum sp. had a greater capacity to concentrate the limiting L-lactate from the environment. This was indicated by its higher affinity and more active transport system for L-lactate and by its higher surface to volume ratio. The increase in surface to volume ratio in the two bacteria 
in response to growth at decreasing concentrations of L-lactate was significantly greater in Spirillum sp. than in Pseudomonas sp. This greater uptake capacity for L-lactate must contribute to the advantage of Spirillum sp. at low L-lactate concentrations.

An assessment of the value of $\mu_{\min }$ in the two bacteria was made by investigating the influence of $D$ on their viability, total respiratory capacity and nucleic acid content. The percentage viability of the culture of Pseudomonas sp. dropped markedly below $D=0.05 \mathrm{~h}^{-1}$ and there was a marked discontinuity in the respiratory capacity of the culture below $D=0.08 \mathrm{~h}^{-1}$, suggesting that the $\mu_{\min }$ of Pseudomonas sp. lay in this region. The value obtained from the respiration data is perhaps the more reliable: the recorded percentage viability may be an overestimation of the actual number of growing bacteria in the chemostat since it was determined on a medium which contained a much higher concentration of L-lactate than the chemostat culture at low $D$ values ( $1 \mathrm{~mm}$ as opposed to 1 to $10 \mu \mathrm{M}$ ). Neither loss of viability nor discontinuity in the respiratory capacity of the Spirillum $\mathrm{sp}$. culture was observed in the range of $D$ values examined, indicating that the $\mu_{\min }$ of this bacterium must be below the lowest $D$ value examined. Thus, at $D$ values approximately equal to $\mu_{\min }$ of Pseudomonas sp., Spirillum sp. can still grow normally. This must therefore contribute to its advantage at these $D$ values. Similarly, a lower energy of maintenance on L-lactate, by enabling Spirillum sp. to devote a greater portion of the total available energy to growth processes, must also contribute to its advantage at low L-lactate concentrations. No discontinuity in the nucleic acid content of Pseudomonas sp. was observed when $D$ was lowered below its apparent $\mu_{\min }$ value which is in contrast to the finding of Tempest et al. (1967; see Pirt, 1972).

It is possible that higher concentrations of key catabolic enzymes and/or a higher affinity of these enzymes for their substrate also contribute to the advantage of Spirillum sp. at low L-lactate concentrations. An example of increased activity of a catabolic enzyme leading to faster growth at low substrate concentrations is provided by the 'hyper' mutants of Escherichia coli, which outgrew the wild type at low lactose concentrations, evidently because they synthesized increased levels of $\beta$-galactosidase (Horiuchi, Tomizawa \& Novick, 1962; Smith \& Dean, 1972). The work of Rigby, Burleigh \& Hartley (1974) illustrates the role of the affinity of a catabolic enzyme in the outcome of competition: a mutant of Klebsiella aerogenes possessing a lower $K_{\mathrm{m}}$ for the first enzyme in xylitol metabolism (ribitol dehydrogenase) outcompeted the wild type during xylitol-limited growth in a chemostat.

Spirillum sp. did not prove to be analogous to the 'hyper' $E$. coli mutants with respect to most of the lactate catabolic enzymes, since these activities were significantly lower in Spirillum sp. than in Pseudomonas sp., even after growth at L-lactate concentrations which, in mixed cultures, support faster growth of the former bacterium. The only exceptions were NADH oxidase and cytochrome $c$ levels and, curiously, the cytochrome $c$ content in Spirillum sp., but not in Pseudomonas sp., increased markedly in response to decreasing L-lactate concentration in the environment. We are now investigating whether the higher levels of these respiratory chain components in Spirillum sp. are indicative of a more efficient energy generation during respiration. Attempts were made to compare the $K_{\mathrm{m}}$ values of L-lactate dehydrogenase (NAD-independent) for L-lactate in the two bacteria. In Spirillum sp., this enzyme consisted of three species with different $\mathrm{pH}$ optima and there was a selective increase in two of these activities as the L-lactate concentration in the environment was decreased (A. Matin \& J. Steenhuis, unpublished). It is conceivable that these enzyme species differ in their $K_{\mathrm{m}}$ values for L-lactate and attempts are currently in progress to purify them and determine their $K_{\mathrm{m}}$ values.

The Monod relationships, calculated from $\mu_{\max }$ data and the $K_{\mathrm{s}}$ values determined at $D=0 \cdot 15 \mathrm{~h}^{-1}$, did not account for the degree of advantage of Spirillum sp. over Pseudomonas sp. at $D \leqslant 0 \cdot 24 \mathrm{~h}^{-1}$. According to these relationships, the difference between the the growth rates of the two bacteria at these $D$ values should not be greater than $0.04 \mathrm{~h}^{-1}$; 
in fact, however, Spirillum sp. outgrew Pseudomonas sp. at a rate of $0.06 \mathrm{~h}^{-1}$ at $D=0.05 \mathrm{~h}^{-1}$, and $0.11 \mathrm{~h}^{-1}$ at $D=0.24 \mathrm{~h}^{-1}$. The reason(s) for this discrepancy is not known. The difference in the $\mu_{\min }$ of the two bacteria is probably a contributing factor. Another possibility is that the $\mu-s$ relationships differed at different $D$ values. Several physiological traits in these bacteria were altered in response to culture $D$. Besides the changes reported here, there was, with decreasing $D$, a marked increase in the specific activity of several enzymes of intermediary metabolism as well as in the NAD content of the two bacteria (Matin et al., 1976; Matin \& Gottschal, 1976); such changes could indeed influence the $\mu-s$ relationships. The change in the $K_{\mathrm{s}}$ values of a Spirosoma sp. and a Spirillum sp. in response to temperature have been reported (Wirsen \& Jannasch, 1970; Harder et al., 1977). Furthermore the postulated mechanism of the selection of 'hyper' $E$. coli mutants (Horiuchi et al., 1962) assumes that the increased $\beta$-galactosidase levels in these mutants influence their $K_{8}$ value for lactose (see Dean, 1972). Whether the $\mu-s$ relationships were influenced in our bacteria by culture $D$ was not determined. A third possibility for the discrepancy is that factors related to the interaction of the two populations in mixed cultures contributed to the advantage of Spirillum sp. Apart from excluding the production by Spirillum sp. of an inhibitor of the growth of Pseudomonas sp., the data provide no further information on this point.

Although much remains to be learned about the reasons for the selective advantage of Spirillum sp. in carbon-limited environments, the data clearly establish that in response to the different niches which these bacteria occupy in nature - Spirillum sp., those scarce in nutrients, and Pseudomonas sp., richer ones capable of supporting rapid growth - the two bacteria have evolved a variety of different physiological and morphological characteristics.

We thank F. van Es and S. Ottema for help with some of the experiments and M. Veenhuis for taking the electron micrographs.

\section{REFERENCES}

Calcott, P. H. \& Postgate, J. R. (1972). On substrate-accelerated death in Klebsiella aerogenes. Journal of General Microbiology 70, 115-122.

DEAN, A. C. R. (1972). Influence of environment on the control of enzyme synthesis. Journal of Applied Chemistry and Biotechnology 22, 245259.

DUURSMA, E. K. (1961). Dissolved organic carbon, nitrogen and phosphorus in the sea. Netherlands Journal of Sea Research 1, 1-148.

Harder, W., Kuenen, J. G. \& Matin, A. (1977). Microbial selection in continuous culture. Journal of Applied Bacteriology 43, 1-24.

HoHorst, H. F. (1963). In Methods of Enzymatic Analysis, p. 266. Edited by H. U. Bergmeyer. New York: Academic Press.

Horiuchi, T., Tomizawa, J. \& Novick, A. (1962). Isolation and properties of bacteria capable of high rates of $\beta$-galactosidase synthesis. Biochimica et biophysica acta 55, 152-163.

JANNASCH, H. W. (1967). Enrichment of aquatic bacteria in continuous culture. Archiv für Mikrobiologie 59, 165-173.

JANNASCH, H. W. (1969). Estimation of bacterial growth rates in natural waters. Journal of Bacteriology 99, 156-160.

Kuenen, J. G., Boonstra, J., Schröder, H. G. J. \& VELDKAMP, H. (1977). Competition for inorganic substrates among chemoorganotrophic and chemolithotrophic bacteria. Microbial Ecology 3, 119-130.
Lowry, O. H., Rosebrough, N. J., FARR, A. L. \& RANDALL, R. J. (1951). Protein measurement with the Folin phenol reagent. Journal of Biological Chemistry 193, 265-275.

MatiN, A. \& GotTSCHAL, J. C. (1976). Influence of dilution rate on $\mathrm{NAD}(\mathrm{P})$ and $\mathrm{NAD}(\mathrm{P}) \mathrm{H}$ concentrations and ratios in a Pseudomonas sp. grown in continuous culture. Journal of General Microbiology 94, 333-341.

Matin, A. \& Konings, W. N. (1973). Transport of lactate and succinate by membrane vesicles of Escherichia coli, Bacillus subtilis and a Pseudomonas sp. European Journal of Biochemistry 34, 58-67.

Matin, A. \& VeldKamp, H. (1974). Physiological basis of different substrate affinities of two fresh water organisms. American Society for Microbiology, Abstracts, p. 50. Washington, D.C., American Society for Microbiology.

Matin, A., Grootjans, A. \& Hogenhuis, H. (1976). Influence of dilution rate on enzymes of intermediary metabolism in two freshwater bacteria grown in continuous culture. Journal of General Microbiology 94, 323-332.

Munro, H. N. \& FleCK, A. (1966). The determination of nucleic acids. Methods of Biochemical Analysis XIV, 113-117.

PIRT, S. J. (1972). Prospects and problems in continuous flow culture of microorganisms. Journal of Applied Chemistry and Biotechnology 22, 5564. 
PIRT, S. J. (1975). Principles of Microbe and Cell Cultivation. New York: John Wiley.

Postgate, J. R. (1969). Viable counts and viability. Methods in Microbiology 1, 611-628.

Rigby, P. W. J., Burleigh, Jr, B. D. \& Hartley, B. S. (1974). Gene duplication in experimental enzyme evolution. Nature, London 251, 200-204.

Smith, R. W. \& Dean, A. C. R. (1972). $\beta$-Galactosidase synthesis in Klebsiella aerogenes growing in continuous culture. Journal of General Microbiology 72, 37-47.

Tempest, D. W., Herbert, D. \& Phipps, P. J. (1967). Studies on the growth of Aerobacter aerogenes at low dilution rates in a chemostat. In Microbial
Physiology and Continuous Culture, pp. 240-254. London: H.M.S.O.

VeldKamp, H. (1976). Continuous Culture in Microbial Physiology and Ecology. Durham: Meadowfield Press.

VeldKamp, H. \& JanNasch, H. W. (1972). Mixed culture studies with the chemostat. Journal of Applied Chemistry and Biotechnology 22, 105-123.

Vishniac, W. \& Santer, M. C. (1957). The thiobacilli. Bacteriological Reviews 21, 195-213.

Wirsen, C. O. \& JANNASCH, H. W. (1970). Growth response of Spirosoma sp. to temperature shifts in continuous culture. Bacteriological Proceedings, 32. 